AC22-94pe 93054

\title{
APPENDX6-
}

\section{THE ROLE OF RECYCLE OIL IN DIRECT COAL LIQUEFACTION PROCESS DEVELOPMENT}

\author{
F. P. Burke \\ Prepared for presentation \\ ACS Spring National Meeting \\ Anaheim, CA
}

April 2-7, 1995

\section{DISCLAIMER}

This report was prepared as an account of work sponsored by an agency of the United States Government. Neither the United States Government nor any agency thereof, nor any of their employees, makes any warranty, express or implied, or assumes any legal liability or responsibility for the accuracy, completeness, or usefulness of any information, apparatus, product, or process disclosed, or represents that its use would not infringe privately owned rights. Reference herein to any specific commercial product, process, or service by trade name, trademark, manufacturer, or otherwise does not necessarily constitute or imply its endorsement, recommendation, or favoring by the United States Government or any agency thereof. The views and opinions of authors expressed herein do not necessarily state or reflect those of the United States Government or any agency thereof. 


\section{DISCLAIMER}

Portions of this document may be illegible in electronic image products. Images are produced from the best available original document. 
THE ROLE OF RECYCLE OIL IN DIRECT COAL LIQUEFACTION PROCESS DEVELOPMENT

\author{
F. P. Burke \\ CONSOL Inc., Research and Development \\ 4000 Brownsville Road \\ Library, PA 15102
}

Keywords: Coal, Liquefaction, Recycle 0 il

\begin{abstract}
It has long been recognized that use of a recycle $0 i l$ is a convenient and perhaps necessary feature of a practical direct coal liquefaction process. The recycle oil performs a number of important functions. It serves as a vehicle to convey coal into the liquefaction reactor and products from the reactor. It is a medium for mass and heat transfer among the solid, liquid, and gaseous components of the reactor inventory. It can act as a reactant or intermediate in the liquefaction process. Therefore, the nature of the recycle oil can have a determining effect on process configuration and performance, and the characterization of recycle oil composition and chemistry has been the subject of considerable interest. This paper discusses recycle oil characterization and its influence on the industrial development of coal liquefaction technology.
\end{abstract}

\title{
EARLY GERMAN TECHNOLOGY
}

In the early 1900s, Bergius used a petroleum "heavy oil" as a vehicle to slurry coal in batch and continuous unit liquefaction experiments. 'The German technology utilized in the 1940s was based on further development of the Bergius-Pier process, and utilized high temperature and pressure $(750 \mathrm{~K}, 300 \mathrm{~atm})$ and an inexpensive (and relatively low-activity) iron oxide catalyst (red mud) in a liquid (sump) phase reactor. The recycle solvent was a distillate from gas phase hydrogenation of the sump-phase reactor overheads. Although this technology anticipated the dispersed catalysts under development today, the process employed a high reaction severity, rather than seeking to minimize reaction severity by improved catalyst or solvent activity.

\section{COHSOL SYNTHETIC FUELS PROCESS}

In the $1960 \mathrm{~s}$, Consolidation Coal Company sought to improve on the performance of the German liquefaction technology by utilizing more active supported-metal hydrogenation catalysts in fixed bed reactors. To overcome catalyst deactivation problems, the coal dissolution and catalytic conversion steps of the two-stage CONSOL Synthetic Fuels (CSF) process ${ }^{2}$ were separated by an interstage deashing step. The coal dissolution step was non-catalytic, and carried out at a relatively low temperature to produce an "extract" suitable for catalytic upgrading. The process was designed to produce a distillate hydrogen donor solvent in the second stage. ${ }^{3}$ The role of recycle solvent was explored in bench-scale tests supported by mass spectrometric and ${ }^{1} \mathrm{H}$ - and ${ }^{13} \mathrm{C}$ - nuclear magnetic resonance analys is of the recycle solvent. ${ }^{4}$ This work showed that, a) though the recycle oil increased in molecular weight upon recycle, it became less aromatic (Table 1). Recycle oil characterization was used to indicate the approach of the process operation to steady state, and revealed the important effect of solvent characteristics on other process operations, particularly solids separation.

\section{SOLVENT REFINED COAL PROCESS}

In the mid-1970s, interest grew in the development of a process to convert coal into a fuel-0il substitute for use in oil-fired electric utility boilers. The Solvent Refined Coal (SRC) process was piloted by Gulf at Ft. Lewis, WA, ${ }^{5}$ and by Southern Company Services (and later EPRI) at Wilsonville, AL. " The objective of the process was to solubilize coal under hydrogen, but in a noncatalytic reaction, so that the ash-forming minerals, including pyrite, could be removed by physical means. Some organic sulfur removal also was expected. The deashed products were distilled to yield the SRC product and a distillate recycle solvent. One objective was to produce only enough distillate to remain in solvent balance. This would ensure the maximum yield of the desired SRC product, while minimizing hydrogen consumption.

Because the SRC process was designed as a thermal distillate-recycle process (perhaps aided by the catalytic effect of the coal ash), the operating conditions had to be chosen to achieve satisfactory coal conversion, SRC yield, and desulfurization, while maintaining an adequate yield of recycle solvent. In practice, this proved to be a difficult balance to achieve. Higher reaction temperature 
tended to improve coal conversion and reduce SRC sulfur, but increased gas make at the expense of recycle solvent and SRC yield.

In addition, because the distillate yield in the SCR process was low (typically, less then 5 wt \% MAF coal), the replacement rate of the recycle solvent was low, and changes in solvent composition over time were difficult to assess. Because it was run at relatively constant conditions for long periods of time, and because of its size, the 6 TPD Wilsonville pilot plant became an excellent source of coal liquefaction data and samples for assessing the longer term effects of coal liquefaction on recycle oil quality. In 1977 and 1978, we obtained three relatively large and representative samples of the recycle distillate from Wilsonville for use in bench-scale liquefaction research. Some of the solvents were catalytically hydrogenated in a bench scale unit. These samples were the basis for an extensive characterization effort, ${ }^{8}$ which included ${ }^{1} \mathrm{H}$-NMR and ${ }^{19} \mathrm{~F}-$ NMR (for phenol determination following derivatization), GC/MS, FIMS, reverse phase liquid chromatography, and empirical tests of solvent quality.

As the distillate recycle solvent in the SRC-I process evolved (Tables 2 and 3 ), it increased in total hydrogen content, but was lower in molecular weight, more aliphatic, and more phenolic. The practical consequence, as indicated by the microautoclave solvent quality tests, was that it lost hydrogen donating ability. The underlying structural changes were revealed by the NMR and FIMS data. The overafl decrease in aromaticity was totally at the expense of the condensed aromatic structures; uncondensed aromatic hydrogen actually increased. The increase in aliphatic hydrogen appeared in both cyclic and aliphatic regions initially, but as the solvent further evolved, the cyclic aliphatic hydrogen decreased. The apparent loss of hydrogen donor activity under kinetic control (KIN test) was associated with the decrease in condensed aromatic hydrogen. The decrease in conversions at the EQ conditions, designed to measure donor hydrogen content, was associated with the ratio of cyclic to alkyl aliphatic hydrogen. FIMS analysis (Figures 1 and 2) showed that catalytic hydrogenation of the more aromatic solvent ( $8 / 77$ sample) converted aromatics to hydroaromatics and improved solvent quality. Although solvent evolution increased hydrogen content (and alkyl tetral in) by an amount similar to catalytic hydrogenation, it decreased the concentration the aromatics and the corresponding hydroaromatics.

SELECTIVE RECYCLE AS AN IMPROVED LIQUEFACTION OPTION

The research on the evolution of the SRC distillate solvent clearly indicated the importance of higher molecular weight hydroaromatics as hydrogen donor solvent components. However, the low distillate yield in the SRC process provided few options for improving the situation, leading to the conclusion that recycle of vacuum bottoms, or a vacuum-bottoms component, would be necessary to maintain solvent quality. ${ }^{8}$. This concept was tested by separating the SRC into "light" and "heavy" components and using the light SRC (LSRC) as a component of the recycle solvent in bench scale and microautoclave liquefaction experiments. 9 In the microautoclave experiments, the LSRC was added to the Wilsonville solvent sample during 4/78. The addition of LSRC improved solvent quality at the "Kinetic" conditions (Table 4), but decreased conversion at the "Equilibrium" conditions indicating that it contained active hydrogen donors, but not in large concentration. The improvement seen at the EQ conditions under hydrogen pressure were somewhat surprising and the degree of improvement was remarkable. These results clearly indicated that this non-distillate oil was capable of facilitating gas phase hydrogen utilization for coal conversion in the absence of an added catalyst.

THE ROLE OF PARAFFINS IN SOLVENT QUALITY

Not all solvent quality effects can be ascribed to the activity and concentration of hydrogen donors. There has been a tendency to think in terms of "average" structures in describing coal and coal products. However, coal liquids are much more heterogeneous than an average structure might suggest. One feature of solvent quality that the FIMS data failed to reveal was the concentration of straight-chain and branched paraffinic components in recycle oils; FIMS is relatively insensitive to paraffins. In one case, the recycle distillate from a Wilsonville ITSL run with subbituminous coal produced a $47 \%$ wax yield upon ketone dewaxing; $12 \mathrm{wt \%}$ of the recycle distillate consisted of $n$-paraffins. ${ }^{10}$ Simple physical removal of this wax fraction increased the solvent quality in the EQ microautoclave test from $71 \%$ to $87 \%$.

\section{SIMGLE STAGE CATALYTIC LIQUEFACTIOH}

The $H$-Coal process employs a single ebullated-bed reactor to convert coal to distillate products. In PDU and pilot plant development, a relatively high reaction temperature $\left(825-840^{\circ} \mathrm{F}\right)$ and resid recycle were used to achieve high 
conversion while minimizing reactor residence size. Compared to the SRC process, H-Coal approached a steady state recycle composition quickly" because of the higher turnover rate of the recycle oil components. The process solvent increased in aromaticity and phenolic $-\mathrm{OH}$ content with run time, corresponding to catalyst deactivation. Characterization of the recycle oil during the PDU runs was used to determine the approach steady state composition. The results indicated that the residual recycle components, particularly the preasphaltenes, reached a consistent composition relatively early in the run, but the degree of hydrogenation of the recycle distillate decreased throughout the run. This suggested that the rate of catalyst deactivation was relatively more rapid for the larger resid molecules than for the smaller distillate molecules.

\section{INTEGRATED THO-STAGE LIQUEFACTION}

The idea of separating the coal dissolution and catalytic upgrading functions was further evaluated in the development of the Lummus Integrated Two-Stage Liquefaction Process. The Lummus ITSL process used a short-residence-time (SRT), high temperature $\left(850^{\circ} \mathrm{F}\right)$ coal conversion stage, followed by anti-solvent deashing. The deashed oil was converted to liquid products in an expanded-bed catalytic reactor (LC-Finer), which was operated at a lower temperature (720-750 ${ }^{\circ} \mathrm{F}$ ) than the $\mathrm{H}$-Coal reactor. The recycle oil from the second stage contained distillate and unconverted resid. Because of the thermal first stage, solvent quality was an important factor in process performance. The reactor configuration also provided an opportunity to investigate the separate roles of catalytic and thermal reactions in direct liquefaction. Comparison of the process $0 i 1$ characteristics in the Lummus ITSL process to those from single-stage $\mathrm{H}$-Coal process were particularly instructive. 12 The results showed that hydrogen donor solvent quality was a key to coal conversion in the SRT first stage, and promoted thermal resid conversion in both stages. The lower temperature of the LC-Finer, compared to that of the $\mathrm{H}$-Coal reactor, produced a more highly hydrogenated resid that underwent considerable thermal conversion in the short-residence-time, high temperature first stage. The temperature of the LC-Finer al so contributed to the maintenance of distillate solvent quality by minimizing cracking and isomerization reactions that could remove hydroaromatics and their precursors (Table 5). Most of the development work for ITSL was done with mid-continent bituminous coals, and a limitation was revealed when the process was applied to subbituminous coals. Despite the good solvent quality, coal conversion was kinetically limited, necessitating the use of a longer residence time in the first stage reactor. The Lummus work also demonstrated that interstage deashing was not necessary to maintain catalyst activity, because catalyst activity loss was primarily a function of carbon deposition, which occurred regardless of the presence of solids.

Extensive further development work was done on the two-stage process at the Wilsonville pilot plant, in a wide variety of configurations. ${ }^{3}$ The Wilsonville operators concluded that it was necessary to use a dispersed iron oxide catalyst to achieve satisfactory conversions with subbituminous coal. Essentially all of the work with bituminous coals was done with two ebullated-bed catalytic reactors in series. Hoderate reactor temperatures, low space velocities, and high catalyst replacement rates (relative to $\mathrm{H}$-Coal), and close-coupling of reactor stages (i.e., no interstage deashing) resulted in improved yields, product quality, and selectivity. The use of a critical solvent deasher (ROSE-SR) unit allowed considerable flexibility in controlling recycle composition. The plant employed high recycle rates of heavy distillate $\left(>750^{\circ} \mathrm{F}\right.$ IBP), resid, and unconverted coal to reduce the required per-pass conversion level. The result of these changes was a departure from the original two-stage concept of separating thermal coal dissolution and resid upgrading. Most of the feed to the first stage was recycled resid.

Subsequent work has shown that the insoluble organic matter (IOM) in the recycle resid from Wilsonville is reactive for further conversion, and methods to improve solvent quality by dewaxing and hydrogenation are being evaluated. ${ }^{14}$ This work will provide the opportunity to better define the role of recycle solvent quality in the current generation of two stage catalytic liquefaction processes.

\section{CONCLUSIONS}

This paper was not intended as a comprehensive review of the subject of recycle oil chemistry, but rather as a perspective on the changing perception of the role of recycle or solvent-mediated phenomena in direct liquefaction process development. In the earlier US work on direct liquefaction, the goal of separating the thermal coal dissolution and catalytic distillate production steps led to process configurations that relied on hydrogen donor solvents for coal conversion. Research showed that the distillate recycle solvents which evolved under mostly 
thermal conditions were poor hydrogen donors, but that selective recycle of higher molecular weight components improved both donor content and activity. When it was realized that interstage deashing had little practical benefit, conversion of the coal in a catalytic first stage diminished the perceived need for an active hydrogen donor solvent. For subbituminous coals, donor solvent hydrogen alone did not appear to be adequate to achieve satisfactory conversions, leading to the use of dispersed catalysts, greater reaction severity, and solids recycle. However, the improvements of two-stage 1 iquefaction came at the expense of reduced space velocity and increased catalyst usage. Current research is looking to replace the supported-catalyst systems with dispersed catalysts that offer higher selectivity and activity, while avoiding the capital cost of a supported-catalyst system. As this research and development continues, it will be important to understand and evaluate the role of vehicle solvents, and to look for opportunities to utilize solvent-mediated reactions as part of a overall strategy for reducing the cost of producing liquids from coal.

\section{ACKNOHLEDGEMENT}

The work discussed in this paper was supported by the CONSOL Inc., the U.S. Department of Energy, and the Electric Power Research Institute. I am indebted to many colleagues, particularly those at CONSOL, DOE, EPRI, HRI, the Wilsonville Advanced Liquefaction Test Facility, and Lummus-Crest for their contributions to this work.

1. Bergius, F., German Patent No. 301,231, August 9, 1913.

2. Gorin, E.; Kulik, C. J.; Lebowitz, H. E. Ind. End. Chem. Process Des. Dev. $1977,1695$.

3. Curran, G. P.; Struck, R. T.; Gorin, E. Ind. Eng. Chem Process Des. Dev. $1967,6,166$.

4. Kleinpeter, J. A.; Jones, D. C.; Dudt, P. J.; Burke, F. P. Ind. Eng. Chem. Process Des. Dev. 1979, 18, 535.

5. Pittsburg and Midway Coal, "Solvent Refined Coal (SRC) Process, Annual Report, 1976", DOE Report FE-496-131 (Hay 1977).

6. Lewis, H. E.; Heber, W. H.; Usnick, G. B.; Hollenack, W. R.; Hooks, H. W. "Solvent Refined Coal (SRC) Process. Operation of Solvent Refined Coal Pilot Plant at Wilsonville, Alabama. Annual Technical Progress Report, January-December, 1976", DOE Report No. FE-2270-15 (June 1977).

7. Styles, G. A.; Weber, W. H.; Basu, A. "Short Residence Time Studies Utilizing the Dissolver Preheater at the Wilsonville SRC Pilot Plant", Proceedings, EPRI Contractor's Conference on Coal Liquefaction, Palo Alto, May 1978.

8. Burke, F. P.; Winschel, R. A.; Pochapsky, T. C. "Composition and Performance of Distillate Recycle Solvents from the SRC-I Process", Fuel 1981, 60, 563.

9. Kleinpeter, J. A.; Burke, F. P. "Conventional and Short Residence Time Coal Liquefaction Using Selective Product Recycle", Proceedings, EPRI Contractor's Conference on Coal Liquefaction, Palo Alto, May 1979.

10. Winschel, R. A.; Robbins, G. A.; Burke, F. P. "Improvement in Coal Liquefaction Solvent Qual ity by Dewaxing", Fuel 1987, 66, 654 .

11. Burke, F. P.; Winsche1, R. A. "Slurry Recycle 0il Composition and Process Performance in H-Coal PDU Operations", Proceedings, Sixth Annual EPRI Contractor's Conference, Palo Alto, May 1981.

12. Winschel, R. A.; Burke, F. P. "Process and Product 0 il Characterization in Two Stage Coal Liquefaction", Proceedings, Eighth Annual EPRI Contractor's Conference on Coal Liquefaction, Palo Alto, May 1983.

13. Lee, J. M.; Vimalchand, P.; Cantrel1, C. E.; Davies, 0. L. "Major Accomplishments at the Advanced Coal Liquefaction Test Facility at Wilsonville", DOE Liquefaction Contractors' Review Conference, Pittsburgh, September 1992.

14. Derbyshire, F. J. "Improved Coal Liquefaction through Enhanced Recycle Distillate Quality", Proceedings, DOE COal Liquefaction Contractors' Conference, September 1993. 
Table 1. Proton Distributions of Recycle Solvents in the CSF Process

Cycle 1

Cyclo 2

Cycle 3

Cyclo 4

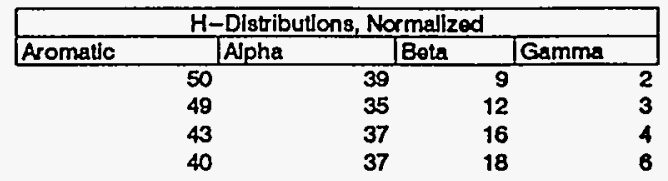

Table 2. Characterization of Recycle Solvents trom Wilsonville SRC-1 Operations

\begin{tabular}{|c|c|c|c|c|c|c|c|c|}
\hline \multirow{3}{*}{$\begin{array}{c}\text { Sample } \\
\text { Date }\end{array}$} & \multicolumn{5}{|c|}{ Hydrogen, $w+\%$} & \multirow{3}{*}{$\begin{array}{l}-\mathrm{OH} \\
\mathrm{meg} / \mathrm{g}\end{array}$} & \multicolumn{2}{|c|}{ Solvent Quality } \\
\hline & \multirow[b]{2}{*}{ Total } & \multicolumn{2}{|c|}{ Aromatic } & \multicolumn{2}{|c|}{ Alphatic } & & \multirow[t]{2}{*}{$\mathrm{KIN}$} & \multirow[t]{2}{*}{ EQ } \\
\hline & & Condensed & Uncond & Oycile & Alkyl & & & \\
\hline $8 / 77$ & & 2.1 & 0.90 & 1. & 2. & 1.2 & 81. & 76.5 \\
\hline $4 / 78$ & & 1.3 & 0.85 & 2. & 4. & 1.5 & 78.5 & 74.4 \\
\hline $10 / 78$ & & 1.2 & 1.09 & 1. & 4. & 1.6 & 75. & 67.4 \\
\hline Hydro $(8 / 77)$ & & 1.8 & 0.83 & 2 & 3. & 0.6 & 80. & 85.6 \\
\hline
\end{tabular}

Table 3. Comparison of Wilsonville Solvents by FIMS

Table 4. Effect of Kerr-McGoe Ught SRC addtion on Wilsonville solvent quality ( $4 / 78$ sample)

\begin{tabular}{|c|c|c|}
\hline \multirow{2}{*}{$\begin{array}{l}\text { Naphthalone } \\
\text { Totralln/lndans }\end{array}$} & \multicolumn{2}{|c|}{\begin{tabular}{|c|} 
Differ onces, mol $\%$ of total liquld \\
Batch V - Batch I Hydro - Batch I \\
\end{tabular}} \\
\hline & -0.9 & -2.1 \\
\hline Mass 178 & $\begin{array}{r}4.0 \\
-3.1\end{array}$ & $\begin{array}{r}3.1 \\
-1.5\end{array}$ \\
\hline Hydro Mass 178 & -1.9 & 2 \\
\hline Mass 202 & -1.1 & -0.6 \\
\hline Hydro Mass 202 & -0.7 & 1.3 \\
\hline Carbazole & -0.1 & \\
\hline $\begin{array}{l}\text { Quinolines } \\
\text { Hydroquinolines. }\end{array}$ & & $\begin{array}{r}-1.1 \\
0.3\end{array}$ \\
\hline & 1.3 & -1.4 \\
\hline Phenols & 5.9 & -0.2 \\
\hline
\end{tabular}

\begin{tabular}{|c|c|c|c|}
\hline \multirow{2}{*}{$\begin{array}{l}\text { LSRC } \\
w+\%\end{array}$} & \multirow{2}{*}{$\begin{array}{c}\mathrm{H} 2 \\
\text { psig cold }\end{array}$} & \multicolumn{2}{|c|}{ Solvent Quality } \\
\hline & & KN & EQ \\
\hline & 0 & 76.5 & 74.4 \\
\hline & 0 & 79.1 & 73.7 \\
\hline & 0 & 88.6 & 65.5 \\
\hline & 1000 & 85.6 & 82.8 \\
\hline & 1000 & 87.6 & 86.2 \\
\hline
\end{tabular}

Table 5. Comparison of Lummus ITSL (Run 2SCT9) and H-Coal (POU Run 9) Recyclo Distillates

\begin{tabular}{l|r|r|} 
& \multicolumn{3}{c|}{ Concentraton, wt\% } \\
\cline { 2 - 4 } Aromatics & TSL & H-Coal \\
n-Alkyl Aromatics & 12 & 8 \\
Hydrosomatics & 10 & 20 \\
Cyclo-Penta Arom & 31 & 8 \\
n-Alkanes & 6 & 18 \\
& 1 & 6
\end{tabular}

$\frac{x}{8}$
$\overline{8}$
$\frac{8}{8}$
8
$\frac{5}{8}$
$\frac{8}{8}$
$\frac{8}{5}$
8

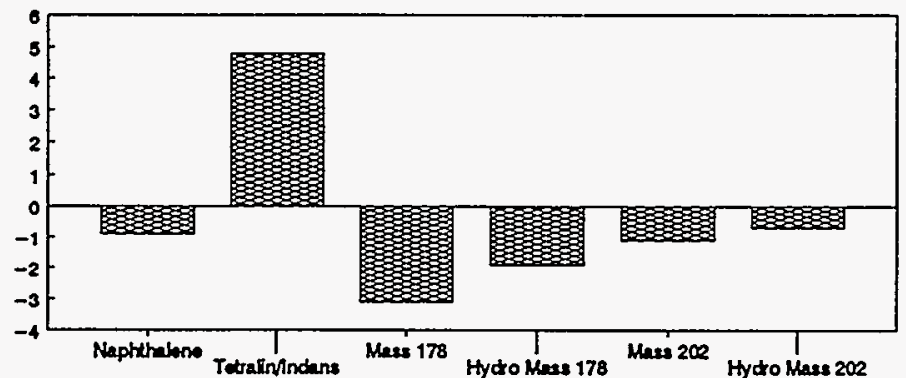

Figure 1. FIMS Comparison: Batch VI-Batch I.
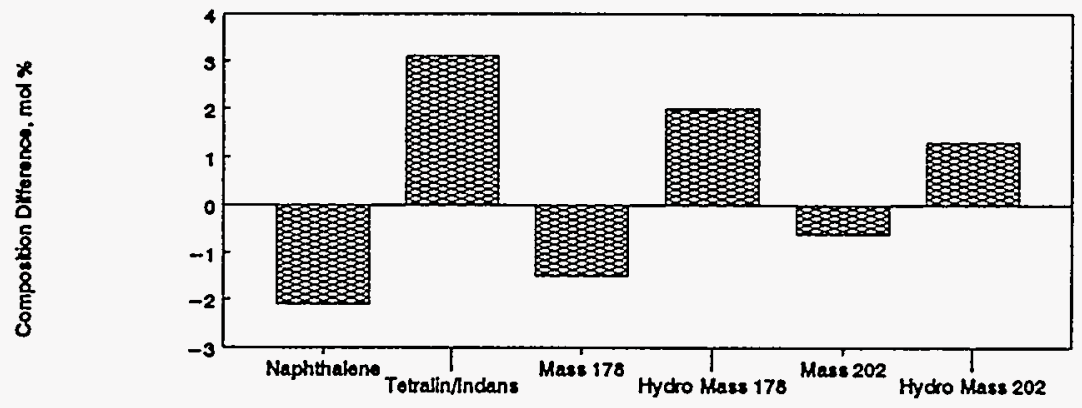

Figure 2 FIMS Comparlson: Hydro 1-Batch 1. 